\title{
Deformation of zirconium - niobium alloy E635 in sub-microsecond shock waves
}

\author{
D.N. Kazakov, O.E. Kozelkov, A.S. Mayorova, S.N.Malyuginaa ${ }^{a}$, S.S. Mokrushin, and A.V. Pavlenko
}

RFNC-VNIITF, 456770, Snezhinsk, Chelyabinsk region, Russia

\begin{abstract}
Strength characteristics of zirconium - niobium alloy E635 were measured under shock - wave loading conditions at normal and elevated temperatures and results of these measurements are presented. Measurements were taken in conditions when samples were impacted by plane shock waves with the pressure up to $13 \mathrm{GPa}$ and duration from $\sim 0.05 \mu \mathrm{s}$ up to $1 \mu \mathrm{s}$. Free-surface velocity profiles were recorded with the help of VISAR and PDV laser Doppler velocimeters having nanosecond time resolution. Evolution of elastic precursors with samples thickness varying from 0.5 up to $8 \mathrm{~mm}$ is also considered. Measured attenuation of the elastic precursor was used to determine plastic strain rate behind the precursor front. Temperature effect on the value of dynamic elastic limit and spall strength at normal and elevated temperatures is studied.

This work is implemented with the support of the State Atomic Energy Corporation "Rosatom" under State Contract H.4x.44.90.13.1111.
\end{abstract}

\section{Introduction}

Zirconium and alloys on its basis are main structural materials in nuclear power engineering. Small thermal neutron capture cross-section, high-temperature strength, high resistance to creep and irradiation-induced swelling, and also high corrosion resistance together with good compatibility with nuclear fuel make these materials to be most suitable for shells and other elements of fuel assemblies [1,2].

Use of products made from zirconium and its alloys under high temperatures and also the necessity to predict behavior of these materials both in severe operational conditions and probable emergency situations highlights importance of the issue how temperature effects elasticplastic and mechanical strength characteristics of these materials under high-strain-rate deformation. Investigation into processes of elastic-viscous-plastic deformation of metals and alloys under shock-wave loading [3] allows us to measure velocity-temperature relationships how these materials resist to deformation and fracture. The structure of shock waves in solid bodies depends on processes of their elastic-viscous-plastic deformation, possible phase transformations, as well as on kinetics of fracture incipience and development [4-6].

Available experimental data on dynamic characteristics of zirconium alloys in the range of high strain rates are insufficient to construct wide-range models of elasticviscous-plastic deformation. At the same time when strain rates are higher than $10^{4} \mathrm{~s}^{-1}$, dependence of the flow and fracture stresses sharply increases in many metals due to a changed mechanism of dislocation movement [3,4].

Zirconium alloy E635 $(\mathrm{Zr}-1.0 \% \mathrm{Nb} ; \sim 1 \% \mathrm{Sn} ; \sim$ $0.5 \% \mathrm{Fe})$ as well as E110 $(\mathrm{Zr}-1.0 \% \mathrm{Nb})$ - are the main commercial alloys for nuclear power engineering.

\footnotetext{
${ }^{a}$ Corresponding author: svetlana_malyugina@mail.ru
}

This paper presents results given by investigations into strength characteristics of zirconium alloy E635 in submicrosecond shock-waves at strain rates of $10^{4}-10^{6} \mathrm{~s}^{-1}$ and also compares its characteristics with those of zirconium alloy E110.

Measurements were taken in the experimental setup when plane shock waves impacted samples in wellcontrolled loading conditions within 4-12 GPa. Shock load duration varied from 0.05 up to $1 \mu \mathrm{s}$. The material was studied in the $\alpha$ - phase under normal and elevated temperatures and in the $\beta$ - phase (under higher than $900{ }^{\circ} \mathrm{C}$ temperature).

\section{Material and experimental setup}

Zirconium - is a polymorphous metal that has a hexagonal close-packed lattice under normal conditions and belongs to transition metals. Zirconium alloy E635 contains niobium (0,9-1,1 mass\%), tin (1.1..1.4 mass\%), and iron (0.3..0.47 mass\%) as main alloying components. The rest admixtures (hafnium, nickel, chromium, carbon, silicon, etc.) in the aggregate do not exceed $0.25 \%$. The alloy has $6.49 \mathrm{~g} / \mathrm{cm}^{3}$ density, $500 \mathrm{MPa}$ yield strength, and $590 \mathrm{MPa}$ ultimate strength [7]. The X-ray diffractometry demonstrated that the test material is a two-phase material. Insignificant presence of the $\beta$ - phase (bcc lattice) is observed in addition to the $\alpha$-phase (hcp lattice).

The material was studied in the as-received condition. The rod with the $35-\mathrm{mm}$ diameter was sliced into disks with the thickness of $0.3,0.5,1.0,2,4$, and $8 \mathrm{~mm}$ to serve as zirconium alloy E635 samples for tests. The ultrasonic technique and samples with the 8-mm thickness were used to determine longitudinal $c_{l}$ and shear $c_{s}$ sound velocities: $c_{l}=4711 \pm 12 \mathrm{~m} / \mathrm{s}$ and $c_{s}=2274 \pm$ $2 \mathrm{~m} / \mathrm{s}$. Volume sound velocity was estimated to be $c_{0}=$ $3.91 \mathrm{~km} / \mathrm{s}$. In order to estimate stresses arising in the 
Table 1. Setting Data on experimental setups and measured strength characteristics of zirconium alloy E635.

\begin{tabular}{|c|c|c|c|c|c|c|c|}
\hline \multirow{2}{*}{$\begin{array}{l}\mathbf{V}_{\mathbf{0}} \\
\mathbf{m} / \mathbf{s}\end{array}$} & \multirow{2}{*}{$\begin{array}{l}\mathbf{h}_{\mathbf{i}}, \\
\mathbf{m m}\end{array}$} & \multirow{2}{*}{$\begin{array}{l}\mathbf{h}_{\mathbf{s}}, \\
\mathbf{m m}\end{array}$} & \multirow{2}{*}{$\begin{array}{l}W_{h}, \\
\mathrm{~m} / \mathrm{s}\end{array}$} & $\sigma_{\mathrm{h}}$ & $\boldsymbol{\sigma}_{\tau}$ & $\sigma_{\mathrm{sp}}$ & \multirow{2}{*}{$\begin{array}{l}\mathbf{S R}_{\text {rw }}, \\
\mathbf{s}^{-1}\end{array}$} \\
\hline & & & & \multicolumn{3}{|c|}{ GPa } & \\
\hline 630 & 1,99 & 3,977 & 64 & 0,98 & 0,46 & 2,88 & 0,13 \\
\hline 303 & 1,972 & 3,972 & 66 & 1,01 & 0,47 & 2,79 & 0,1 \\
\hline 644 & 0,116 & 0,476 & 85 & 1,30 & 0,57 & 3,38 & 1,16 \\
\hline 652 & 0,980 & 0,981 & 80 & 1,22 & 0,57 & - & - \\
\hline 655 & 0,997 & 1,981 & 62 & 0,95 & 0,44 & 2,81 & 0,24 \\
\hline 646 & 0,454 & 0,983 & 71 & 1,09 & 0,49 & 3,06 & 0,58 \\
\hline 945 & 2,013 & 3,985 & 58 & 0,89 & 0,41 & 2,67 & 0,14 \\
\hline 930 & 0,993 & 1,993 & 69 & 1,05 & 0,49 & 2,89 & 0,31 \\
\hline 616 & 0,116 & 0,426 & 89 & 1,36 & 0,67 & 3,82 & 1,50 \\
\hline 616 & 0,116 & 0,315 & 89 & 1,36 & 0,63 & 3,83 & 1,30 \\
\hline 595 & 3,984 & 7,963 & 57 & 0,87 & 0,41 & 3,06 & 0,067 \\
\hline 606 & 3,976 & 7,963 & 56 & 0,86 & 0,40 & 2,83 & 0,73 \\
\hline 638 & 1,992 & $3,962 *$ & 71 & 1,09 & 0,46 & 2,72 & 0,127 \\
\hline 555 & 2,00 & $4,00 * *$ & & & & 2,23 & 0,07 \\
\hline
\end{tabular}

$*$ Temperature of sample $331^{\circ} \mathrm{C}$,

** Temperature of sample $960^{\circ} \mathrm{C}$

samples, we used Hugoniot adiabat of zirconium $D=$ $3.91+0.91 u(\mathrm{~km} / \mathrm{s})$, where $D-$ is shock wave velocity, $u$ - is mass velocity [8] with a correction for sound velocity data obtained for alloy E635.

Shock-wave experiments to record the sample deformation dynamics used a light-gas gun of the 44-mm caliber [9] in the range of impact velocities from 300 to $950 \mathrm{~m} / \mathrm{s}$. The plane shock wave in samples having 1,2 , 4 , and $8-\mathrm{mm}$ thickness was generated by an impactor of zirconium alloy E635 with the thickness of 0.5, 1, 2, and $4 \mathrm{~mm}$, respectively. With samples having 0.5 and $0.3-\mathrm{mm}$ thickness, an impactor made from the zirconium foil with the $0.1-\mathrm{mm}$ thickness was used to generate a shock wave.

Impact velocity was measured with the error at least $0.5 \%$. In experiments out-of-parallelism of impacting surfaces was $\sim 1 . .2 \mathrm{mrad}$. Experiments were performed in conditions of vacuum.

Resistance heaters were used for tests under elevated temperatures in order to heat up samples to the required temperatures. Temperature was monitored with the accuracy of $\pm 5^{\circ} \mathrm{C}$ by thermocouples fixed at the lateral surface of samples.

In experiments, velocity of the sample free-surface was continuously recorded with the help of VISAR [10] and PDV [11] techniques. Time resolution of VISARinterferometer is at least $2 \mathrm{~ns}$, velocity resolution of PDV-interferometer is at most $1 \%$ within the velocity range under consideration. Amplitude resolution of the interferometer is at most $1 \%$, time resolution - is at least $4 \mathrm{~ns}$. The Hilbert method was used to process PDV data.

\section{Measurement results}

Table 1 gives basic data on the setup of shockwave experiments, as well as certain measured strength characteristics of zirconium alloy E635.

We also used the following designation: $V_{0}$ - impact velocity, $h_{i}$ - impactor thickness, $h_{s}$ - sample thickness, $W_{h}$ - velocity at the front of the elastic precursor, $\sigma_{h}=$

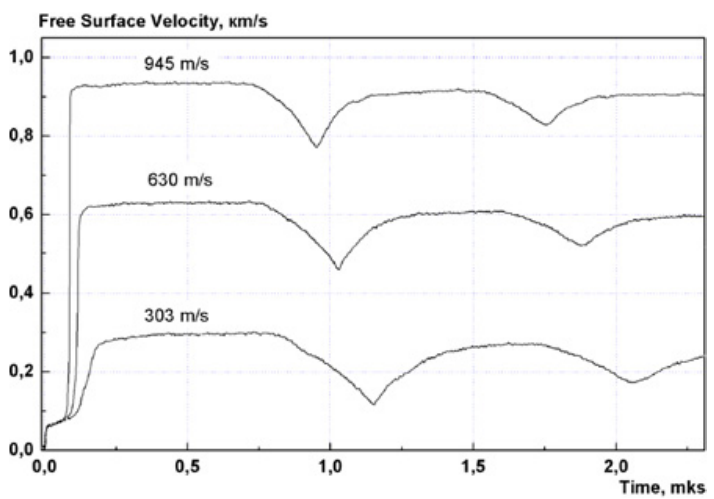

Figure 1. Free-surface velocity profiles for zirconium alloy E635 samples.

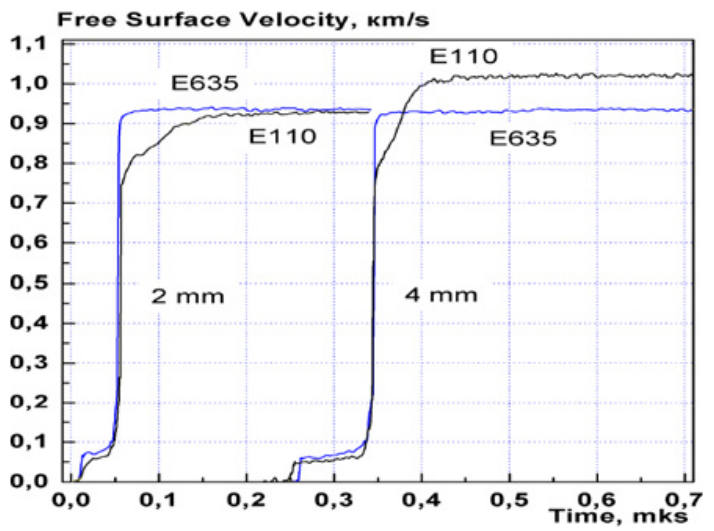

Figure 2. Free-surface velocity profiles for samples from zirconium alloys E635 and E110. Thickness of samples: 2 and $4 \mathrm{~mm}$.

$\sigma_{H E L}-$ dynamic elastic limit, $\sigma_{\tau}-$ dynamic yield stress, $\sigma_{s p}$ - spall strength, $S R_{r w}-$ strain rate in a rarefaction wave $\left(V^{\prime} / V_{0}\right)$.

The value of the dynamic elastic limit

$$
\sigma_{H E L}=\rho_{0} c_{l} W_{h} / 2
$$

agrees with conditions of uniaxial deformation; this value is converted to the yield strength in standard conditions of uniaxial stressed state $\sigma_{\tau}$ using a simple relationship

$$
\sigma_{\tau}=3 / 2 \sigma_{H E L}\left(1-\left(c_{b} / c_{l}\right)^{2} .\right.
$$

Figure 1 shows characteristic free-surface velocity profiles $W(t)$ for samples from zirconium alloy E635 at differentintensity impacts. An impactor velocity is given above each profile.

Free-surface velocity profiles for samples made from zirconium alloy E635 are observed to have a twowave configuration of the shock wave with its splitting into the elastic precursor and the plastic compression wave propagating behind the precursor. For comparison in samples from zirconium alloy E110 under loading amplitudes above $10.6 \mathrm{GPa}$, the elastic and phase precursors are recorded in front of the principal plastic wave due to the polymorphous $\alpha \rightarrow \omega$ transition with the decrease of the specific volume (see Fig. 2) [12, 13].

The portion of steady-state flow (Fig. 1) is followed by the decrease of rarefaction wave parameters. Interaction 


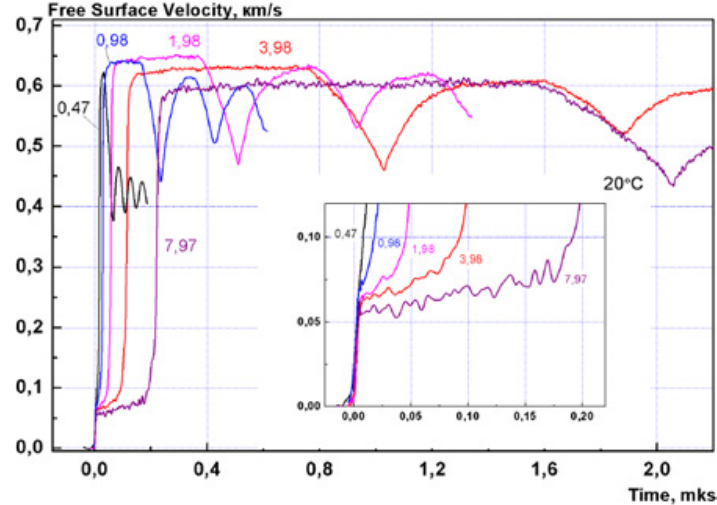

Figure 3. Free-surface velocity profiles for Zirconium alloy E635 samples. Profiles have nominal thickness of samples $\left(\mathrm{T}=20^{\circ} \mathrm{C}\right)$.

of the incident and reflected rarefaction waves causes generation of tensile stresses inside the sample and thus its spall fracturing. За областью стационарного течения (рисунок 1) следует спад параметров в волне разрежения. Relaxation of tensile stresses due to fracturing causes initiation of the compression wave in the stretched material and arrival of this wave at the surface is accompanied by the repeated increase of its velocity, which is called spall pulse. The subsequent periodic fluctuations of the free-surface velocity are conditioned by waves reverberation, i.e. reflection of rarefaction and compression waves from the surface on the separated layer of the material.

Spall strength was estimated based on measured freesurface velocity decrease under unloading from the shockcompressed state taking into account correction for the velocity profile distortion caused by the difference in the velocity of spall pulse and plastic wave propagation in the unloading area [5].

\subsection{Elastic precursor and plastic flow behind its front}

Figure 3 shows free-surface velocity profiles for differentthickness samples from zirconium alloy E635 $\left(\mathrm{V}_{0}-\right.$ $610 . .655 \mathrm{~m} / \mathrm{s}$ ). Each profile has designated thickness of samples.

Our experimental data demonstrate decrease in the elastic precursor amplitude with the compression wave propagation. This is due to stress relaxation during plastic deformation.

Measurement results for the elastic precursor attenuation are given in Fig. 4.

The dynamic elastic limit versus thickness relationship for alloy E110 is given for comparison [13]. Measurement results demonstrate that zirconium alloy E635 has 25..35\% higher dynamic elastic limit compared to E110.

Similar to previous studies [6-9,14-16], attenuation measurement results are approximated by the following empirical relation:

$$
\sigma_{h}=S\left(h / h_{0}\right)^{-\alpha},
$$

where $S=1.158 \mathrm{GPa}, \alpha=0.148$, and $h_{0}=1 \mathrm{~mm}$. The similar data for zirconium alloy E110 $-S=0.87 \mathrm{GPa}, \alpha \approx$ 0.14 .

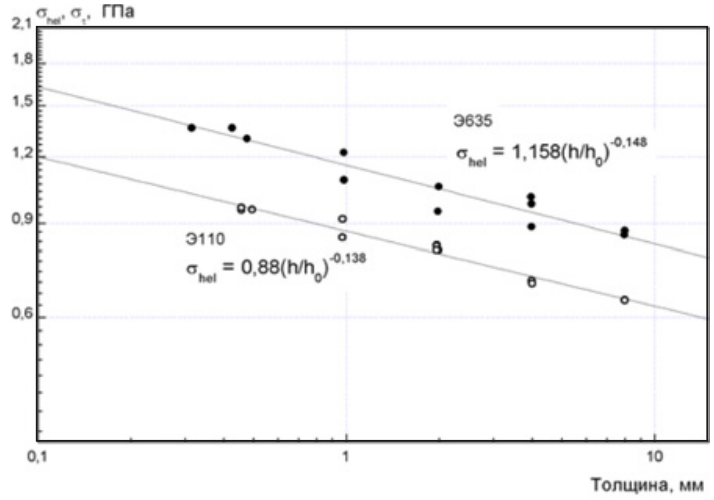

Figure 4. Elastic precursor attenuation in zirconium alloys E635 and E110 [12].

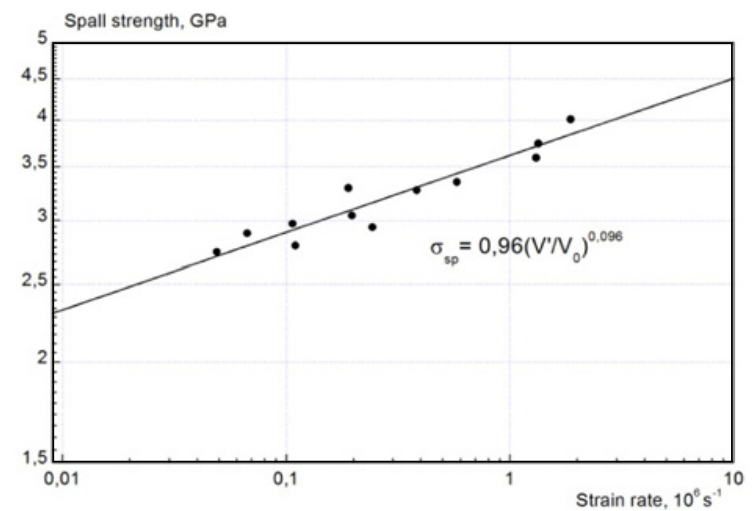

Figure 5. Measured spall strength of zirconium alloy samples versus deformation rate under expansion.

Analysis of elastic precursor attenuation provides information on the initial plastic deformation rate directly after the elastic limit is attained. Measurements of compression velocity in the plastic shock wave provide data on the material behavior at the follow-on stages and usually at higher deformation rates $[17,18]$.

$$
\gamma_{p}^{\prime}=3 / 4\left(\tau E^{\prime} /(S G)\right)^{(\alpha+1) / \alpha} S \alpha c_{l} /\left(h_{0} G\right) .
$$

The plastic strain rate behind the elastic precursor front in alloy E635 ( $\alpha=0.148)$ is comparable with the plastic stain rate in alloy E110 [12.13] with the determining parameter $\alpha \approx 0.14$.

Higher dynamic strength of alloy E635 can be conditioned by the effect of such alloying admixtures as tin and iron.

\subsection{Spall strength}

Figure 5 shows results of processing the stress wave profiles as the "spall strength versus the material expansion rate in the unloading part of the incident compression pulse" relationship.

Spall strength is calculated using approaches described in [5]. Experimental data are acceptably approximated by the following empirical relation:

$$
\sigma_{s p} \sim 0.96\left(V^{\prime} / V_{0}\right)^{0.096} \mathrm{GPa} .
$$




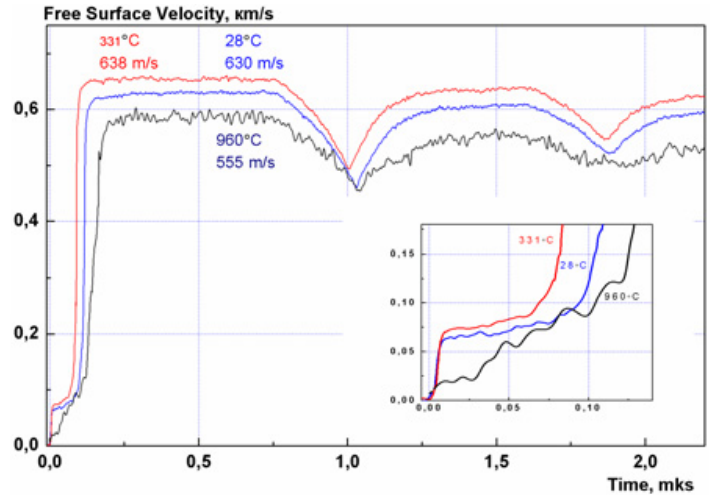

Figure 6. Free-surface velocity profiles $W(t)$ for zirconium alloy E635 samples having 4-mm thickness loaded by the impact of the 2-mm plate from the same material at a rate of $555 . .630 \mathrm{~m} / \mathrm{s}$ under normal and elevated up to $315^{\circ} \mathrm{C}$ and $960^{\circ} \mathrm{C}$ temperatures.

Relationship (5) also determines how the initial rate of discontinuities growth depends on stresses and can be used to construct a macrokinetic models of fracturing.

Experimental data given in Fig. 4 cover the impact load duration range from $\sim 0.05 \mu \mathrm{s}$ up to $1 \mu \mathrm{s}$.

Compared to E110, spall strength of zirconium alloy E635 is less dependent of the strain rate.

\subsection{Temperature effects}

Figure 6 illustrates how the dynamic elastic limit and spall strength of zirconium alloy E635 depend on temperature. With the temperature increase up to $331^{\circ} \mathrm{C}$, the dynamic elastic limit is observed to increase whereas spall strength remains the same.

Wave profiles were processed taking into account temperature relationships of elastic moduli given in [20]. Particularly in this temperature range, shear modulus of zirconium decreases by $20 \%$ and the longitudinal sound velocity - by $3.2 \%$.

Comparison of wave profiles in figure 6 demonstrates $10 \%$ increase in the dynamic elastic limit of zirconium at $331{ }^{\circ} \mathrm{C}$. Spall strength measured at normal and elevated temperatures in the very similar loading conditions underwent no changes and are equal to $2.7 \mathrm{GPa}$ with the regard for measurement error.

At $960^{\circ} \mathrm{C}$, the material shall be in the $\beta$ - phase (bcc lattice). Measurement results demonstrate the twowave profile of the shock wave with its splitting into the elastic precursor and the plastic wave. Spall strength of the material at $960^{\circ} \mathrm{C}$ decreases by $15 . .20 \%$.

\section{Conclusion}

The paper presents measurement results for dynamic characteristics of zirconium alloy E635 in the range of loading duration from $\sim 0.05 \mu \mathrm{s}$ up to $1 \mu \mathrm{s}$ when the pressure amplitude in the shock wave varies from 4 up to $12 \mathrm{GPa}$. Measured relationships of the elastic precursor attenuation were used to estimate the plastic strain rate with the sample thickness from $0.3 \mathrm{~mm}$ to $8 \mathrm{~mm}$. The obtained values are comparable with the plastic strain rate in alloy E110 with samples having similar thickness.
Experiments at temperatures elevated up to $960^{\circ} \mathrm{C}$ are conducted for the first time.

Compared to E110, zirconium alloy E635 has the $25 . .35 \%$ higher dynamic elastic limit. A basic distinctive feature of these alloys is availability in alloy E635 of tin and iron as alloying admixtures. Influence of alloying admixtures is essential. Values of spall strength of zirconium alloys E635 and E110 are comparable.

Spall strength of the zirconium alloy grows with the strain rate as $\sigma_{s p} \sim 0.96\left(V^{\prime} / V_{0}\right)^{0.096}$. Spall strength values for zirconium alloys E635 and E110 are comparable in the considered range of strain rates.

Plastic wave splitting with phase precursor separation registered for alloy E110 under shock-wave amplitudes above $10.6 \mathrm{GPa}$ ( $\alpha \rightarrow \omega$ trnsition) is not observed on the stress-wave profiles for alloy E635 under the shockcompression pressure of 11-12 GPa.

Spall strength changes insignificantly with the temperature increase up to $331^{\circ} \mathrm{C}$. At $960^{\circ} \mathrm{C}$, spall strength decreased by $15 . .20 \%$.

Authors express their sincere gratitude to G.I. Kanel for problem statement and useful discussions during this work implementation.

Very helpful in experiments were E.I. Karnaukhov, M.I. Serkov, M.F. Geraschenko, S.Yu. Filatov.

\section{References}

[1] G.P. Kobylyansky, A.E. Novoselov. Radiation strength of zirconium and zirconium-based alloys. Reference materials on reactor material science. Dimitrovgrad: State Science Center NIIAR. (1996) $176 \mathrm{p}$.

[2] A.S. Zaimovsky, A.B. Nikulina, N.G. Reshetnikov. Zirconium alloys in nuclear power engineering.- M.: Energoatomizdat. (1994).

[3] G.I. Kanel, V.E. Fortov, S.V. Razorenov. Rus.J. UFN ("Uspekhi Fizicheskikh Nauk"- Advances in Physical Sciences), v. 177, № 8, pp. 809-830 (2007).

[4] G.I. Kanel, S.V. Razorenov, A.V. Utkin, V.E. Fortov. Shock-wave phenomena in condensed media. M.: "Yanus -K", p. 408 (1996).

[5] G.I. Kanel. R.J. Rus.J. PMTF (Applied Mechanics and Technical Physics), v. 42, № 2, c. 1-5 (2001).

[6] G.I. Kanel, S.V. Razorenov, A.V. Utkin, V.E. Fortov. Experimental profiles of shock waves in condensed matter. M.: FIZMATLIT (2008).

[7] Material physics: Coursebook for higher educational institutions. Volume 6 , part 1 . Structural materials for nuclear power engineering./ B.A. Kalin, P.A. Platonov, I.I. Chernov, Ya. I. Shtrombakh. - M.: MIFI. (2008). 672 p.

[8] M.V. Zhernokletov, V.N. Zubarev, R.F. Trunin, V.E. Fortov. Experimental data on shock compressibility and adiabatic expansion of condenced matter under high energy densities. Chernogolovka Publisher (1996).

[9] A.V. Pavlenko, S.I. Balabin, O.E. Kozelkov, D.N. Kazakov. Rus.J. PTE, (Instruments and experimental technique), № 4. pp. 122-124 (2013). 
[10] A.V. Pavlenko, S.N. Malyugina, V.V. Pereshitov, I.N. Lisitsyna. Rus.J. PTE, (Instruments and experimental technique), № 2 . pp. 127-129 (2013).

[11] S.S. Mokrushin, N.A. Anikin, S.N. Malyugina, A.A. Tyaktev, A.V. Pavlenko. Rus.J. PTE, (Instruments and experimental technique), № 4, pp.107-110 (2014).

[12] D.N. Kazakov, O.E. Kozelkov, A.S. Mayorova, S.N.Malyugina, S.S. Mokrushin and A.V. Pavlenko, Rus. J. MTT, 6, 77-86 (2014)

[13] S.N.Malyugina, D.N. Kazakov, O.E. Kozelkov, A.S. Mayorova, S.S. Mokrushin and A.V. Pavlenko, In Proc this Conf (2015).

[14] E.B. Zaretsky, G.I. Kanel. Plastic flow in shockloaded silver at strain rates from $104 \mathrm{~s}-1$ to $107 \mathrm{~s}-$ 1 and temperatures from $296 \mathrm{~K}$ to $1233 \mathrm{~K}$. J. Appl. Phys. 110 (7), 073502 (2011).

[15] E.B. Zaretsky and G.I. Kanel. Effect of temperature, strain, and strain rate on the flow stress of aluminum under shock-wave compression. J. Appl. Phys. 112, 073504 (2012).

[16] E.B. Zaretsky and G.I. Kanel. Response of copper to shock-wave loading at temperatures up to the melting point. J. Appl. Phys. 114, 083511 (2013).

[17] E.B. Zaretsky and G.I. Kanel. Tantalum and vanadium response to shock-wave loading at normal and elevated temperatures. Non-monotonous decay of the elastic wave in vanadium. Journal of Applied Physics 115, 243502 (2014).

[18] S.V. Razorenov, G.I. Kanel, G.V. Garkushin, O.N. Ignatova. Rus.J. FTT (Solid State Physics), v. 54, issue 4, pp. 742-749 (2012).

[19] Duvall G.E. In: Stress Waves in Anelastic Solids, edited by H. Kolsky and W. Prager, Berlin: SpringerVerlag. p. 20 (1964).

[20] Guinan M.W. and Steinberg D.J. Pressure and temperature derivatives of the isotropic polycrystalline shear modulus for 65 elements. J. Phys. Chem. Solids, v. 35. pp. 1501-1512 (1974). 